\title{
Relative palatability to sheep of straw, hay and dried grass
}

\author{
By J. F. D. GREENHALGH AND G. W. REID \\ Rowett Research Institute, Bucksburn, Aberdeen $A B{ }_{2}{ }_{9} S B$ \\ (Received 19 October 1970-Accepted 31 December 1970)
}

\begin{abstract}
I. In the first of two experiments four sheep were fed on dried grass and oat straw in the following combinations: (I) straw eaten to appetite and an equal quantity given via a rumen fistula, (2) straw eaten and grass by fistula, (3) grass eaten and straw by fistula, (4) grass eaten and grass by fistula. Mean daily dry-matter intakes $\left(\mathrm{g} / \mathrm{kg}\right.$ metabolic live weight, $\left.W^{0 \cdot 75}\right)$ for the four treatments respectively were: $13.3,23 \cdot 2,47 \cdot 8$ and 59.4 . Dry-matter digestibility coefficients (\%) were $37 \cdot 2,53 \cdot x, 53 \cdot 3$ and $71 \cdot 3$. Changing the digestibility of the diet without changing the component eaten ( 1 v. $2 ; 3 v .4$ ) had a large effect on intake, but changing the component eaten without changing digestibility ( 2 v. 3 ) caused a twofold change in intake. The latter result implied a difference in palatability between the feeds.

2. The quantities of digesta in the rumen, determined by removal before and after feeding, were generally twice as great for treatments 3 and 4 as for 1 and 2 . There were corresponding differences between treatments in the rates of passage of stained particles of feed and of chromic oxide.

3. In the second experiment the treatments were the same except that meadow hay replaced oat straw. Mean daily dry-matter intakes $\left(\mathrm{g} / \mathrm{kg} W^{0.75}\right.$ ) were $41 \cdot 7,55^{\cdot 1}, 59 \cdot 9$ and $68 \cdot 7$ for treatments I to 4 respectively, and digestibility coefficients were $54 \cdot 0,61 \cdot 3,62 \cdot 3$ and $72 \cdot 0$. In this experiment there appeared to be only a small difference in the palatability of the feeds.
\end{abstract}

The term 'palatability' cannot be defined exactly since it is a concept rather than an exact scientific term (Marten, 1969). The palatability of a food is considered to reflect those of its characteristics which invoke a sensory response in the animal. In nutritional science a food is often said to be palatable if it is selected in preference to other foods offered simultaneously. However, in the experiments to be described the question examined was whether or not the ruminant's sensory response to a food affects the quantity of that food it eats when offered no alternative food.

Teitelbaum \& Epstein (1963) examined this question in rats by allowing them to feed themselves solely by stomach tube. The rats had the same calorie intake under these conditions as when they ingested the same diet orally, and it was concluded that sensory stimuli were not essential for the regulation of food intake. The same conclusion was reached by Janowitz \& Hollander (I955), who found that, when dogs were given intragastrically a liquid feed supplying either 50, I00 or $175 \%$ of their normal calorie intake, their calorie intake as solid food was reduced in proportion, so far as this was possible. The liquid feed was given $6 \mathrm{~h}$ before the daily meal of solid food, so oral intake was not limited by gastric distension. More recently, Baile \& Mayer ( $19^{6} 7$ ) have given a liquid diet to goats, the food being either consumed entirely by mouth or given partly through a rumen fistula for $2 \mathrm{~d}$ at a time. In this experiment also, oral intake was reduced by amounts approximately equal to those given intraruminally. The same technique was used for sheep fed on roughages by Weston (I966), with the same result. When the sheep had 200-400 g feed/d put directly into the rumen, their food consumption fell by the same amount; when more 
feed was put into the rumen than the animals would voluntarily consume, digesta accumulated in the rumen and the treatment had to be stopped.

In our experiments, we have used the technique of intragastric feeding, but in a slightly different way. The main factor controlling roughage intake in ruminants is believed to be the maximum rate at which the food can be digested. The rate at which a roughage is digested is often positively related to the extent to which it is digested (i.e to its digestibility), so the intake of a roughage may be related to its digestibility (Blaxter, Wainman \& Wilson, I96I). In our experiments, we have attempted to measure separately the effects of the digestibility of the food and its palatability on the quantity consumed.

A preliminary account of one of the experiments has been published previously (Greenhalgh \& Reid, I967).

\section{EXPERIMENTAL}

\section{Design}

In each of two experiments of Latin square design, two feeds known to be eaten in different amounts were compared by giving them to sheep in four combinations (see Tables $I$ and 3). For two of the treatments, the diet consisted of equal parts of the two feeds. In one (treatment 2) the sheep ate feed $A$ and had an equal amount of feed $B$ put through the fistula; in the other (treatment 3 ) the routes of administration of the feeds were reversed. For the remaining treatments the sheep received either (I) A alone or (4) B alone, and in each instance half the feed was put through the fistula. Thus for treatments 2 and 3 the sheep digested the same diet but ate different components of it, and any difference in intake was attributed to a difference between the components in palatability. For treatments $x$ and 2, and for 3 and 4 , the sheep ate the same components but digested different diets, and differences in intake could therefore be attributed to differences in digestibility.

Immediately after the completion of Expt 2, a small subsidiary trial was made. For two periods the sheep were fed entirely by mouth on either the hay from the main experiment (treatment 5) or the grass (treatment 6 ). Two sheep received treatment 5 followed by 6 and two received 6 and then 5 .

\section{Sheep}

Four Greyface (Border Leicester $\times$ Scottish Blackface) castrated males weighing $40-60 \mathrm{~kg}$ were used. They were $\mathrm{I}-2$ years old at the time of Expt $\mathrm{I}$ and a year older for Expt 2. Each was fitted with a rumen cannula having an internal diameter of $5^{8} \mathrm{~mm}$. They were kept in individual pens and treated periodically for intestinal parasites.

\section{Feeds and feeding procedure}

In Expt I the two feeds were oat straw and dried grass and in Expt 2, the same dried grass was compared with meadow hay. The grass and hay were chopped into lengths of about $20 \mathrm{~mm}$, but the straw had to be further comminuted - by milling through a ${ }_{5} \mathrm{~mm}$ screen - in order to prevent selection by the sheep. The straw contained $3.9 \%$ crude protein in dry matter, the grass, $13.9 \%$ and the hay, $7.7 \%$. 
It was found initially that, if large quantities of dry food were put through the fistula, the animal tended to lose its appetite. If the food was wetted, however, this was not so, and during the experiment food put through the fistula was mixed with four times its weight of warm water. This was approximately the quantity of saliva that would have been mixed with the food if it had been eaten. The fistula feed was given at 09.00 hours each day in an amount equal to half the total quantity of feed taken on the previous day. It was put into the cannula by hand and pushed through with a short rod, a process which took up to ro min for large meals (c. $900 \mathrm{~g})$. Each sheep was then offered the feed taken by mouth until I6.00 hours in an amount sufficient to leave a residue of $15-20 \%$. No food was given between 16.00 hours on one day and 09.00 hours on the next, but water was always available. The sheep also received, through the fistula, a daily supplement of minerals and vitamins $A$ and $D$.

With this procedure it was relatively easy to maintain equal intakes by mouth and fistula. After a preliminary period of at least $\mathrm{I} 2 \mathrm{~d}$ the intake of each sheep was recorded for an experimental period of $9 \mathrm{~d}$.

\section{Faeces collection}

Faeces were collected for $9 \mathrm{~d}$ in each period, beginning $24 \mathrm{~h}$ after the start of the experimental period. The sheep were fitted with harness and bags, the bags being emptied every $24 \mathrm{~h}$, or at shorter intervals when rate of passage of digesta was being measured (see below). Either all or known proportions of the faeces were stored at $0^{\circ}$, then weighed, mixed and sampled at the end of the period.

\section{Measurement of the rate of passage of indigestible residues (Expt $\mathrm{I}$ only)}

On the and day of the experimental period, at I I.00 hours, the sheep were given stained feeds through the fistula in amounts equal to $5 \%$ of daily intake. The straw was stained with brilliant green, and the grass with basic fuchsin, by the method of Castle (1956). For treatments 2 and 3 the sheep received both stained feeds and for I and 4, either one or the other. In addition, all the sheep were given through the fistula $40 \mathrm{~g}$ chromic oxide paper, containing $\mathrm{I}_{3} \mathrm{~g} \mathrm{Cr}_{2} \mathrm{O}_{3}$ (Corbett, Greenhalgh, McDonald \& Florence, 1960).

Faeces were collected for the following $222 \mathrm{~h}$, at twenty intervals $(18 \mathrm{~h} ; 7 \times 6 \mathrm{~h}$; $3 \times 8 \mathrm{~h} ;$ Io $\mathrm{h} ; 6 \times 12 \mathrm{~h} ; 24 \mathrm{~h} ; 3^{2} \mathrm{~h}$ ). The twenty samples for each sheep in each period were stored at $-20^{\circ}$. Stained particles were counted in faecal slurries placed on microscope slides and observed at $8 \times$ magnification. The slides were weighed beforehand and were dried with their contents after counting and reweighed, thus allowing the particle counts to be related directly to faecal dry matter. Chromic oxide was determined by a modification of the method of Stevenson \& de Langen (1960). Cumulative excretion curves for stained particles and chromic oxide were plotted and mean retention time was calculated (Castle, I956).

\section{Measurement of rumen load (Expt $\mathrm{I}$ only)}

The quantity of digesta in the reticulo-rumen of each sheep was measured direct on four occasions in each period, two at 09.00 hours (before feeding) and two at 
I6.00 hours (after feeding). Solid contents were withdrawn through the cannula with a spoon and liquid was poured out by turning the sheep on its side. The rumen was then washed out with several (usually two to four) 21 portions of warm water. The time required to empty the rumen varied according to the amount of material present, between 15 and $45 \mathrm{~min}$. The dry-matter content of the material removed and of the washings was determined by drying samples of 500-1000 $\mathrm{g}$ at $100^{\circ}$.

The remainder of the material removed was then returned to the rumen, and at least $3 \mathrm{~d}$ were allowed to pass before the rumen was emptied again, or before an experimental period was begun.

\section{RESULTS}

\section{Expt I}

Considerable difficulty was experienced with treatment I (straw alone) and, to a lesser extent, with treatment 2 (straw eaten, grass through fistula). Although the sheep ate the straw satisfactorily in a period preceding the experiment, they became increasingly reluctant to do so as the experiment continued. Increasing the protein content of the diet to $8 \%$ by putting casein directly into the rumen failed to increase the intake of straw. In period 2 the sheep on treatment I refused straw completely, and missing values were calculated for it. In periods 3 and 4 the sheep on treatments I and 2 ate a mixture of 10\% grass and $90 \%$ straw rather than straw alone. Over the

\section{Table 1. Expt I. Digestibility and intake of diets based on oat straw and dried} grass, given alone or in combination to sheep

\begin{tabular}{|c|c|c|c|c|c|c|c|}
\hline \multirow{3}{*}{$\begin{array}{l}\text { Treat- } \\
\text { ment } \\
\text { no. }\end{array}$} & & & \multicolumn{2}{|c|}{ Digestibility of } & \multicolumn{3}{|c|}{ Daily intake of } \\
\hline & \multicolumn{2}{|c|}{ Feed consumed } & \multirow{2}{*}{$\begin{array}{c}\text { Dry } \\
\text { matter } \\
(\%)\end{array}$} & \multirow{2}{*}{$\begin{array}{c}\text { Organic } \\
\text { matter } \\
(\%)\end{array}$} & \multirow{2}{*}{$\begin{array}{l}\text { Dry } \\
\text { matter } \\
\text { (g) }\end{array}$} & \multirow{2}{*}{$\begin{array}{c}\text { Dry } \\
\text { matter } \\
\left(\mathrm{g} / \mathrm{kg} W^{0.75}\right)\end{array}$} & \multirow{2}{*}{$\begin{array}{c}\text { Organic } \\
\text { matter } \\
\left(\mathrm{g} / \mathrm{kg} W^{0.75}\right)\end{array}$} \\
\hline & Orally & Intraruminally* & & & & & \\
\hline $\mathbf{I}$ & Straw & Straw (49) & $37 \cdot 2$ & $4 \mathrm{I} \cdot 2$ & I9I & 13.3 & 12.9 \\
\hline 2 & Straw & Grass (49) & $53 \cdot 1$ & $56 \cdot 7$ & 406 & $23 \cdot 2$ & $22 \cdot 0$ \\
\hline 3 & Grass & Straw (5I) & $53 \cdot 3$ & $55 * 4$ & 901 & $47 \cdot 8$ & $45^{\cdot 2}$ \\
\hline 4 & Grass & Grass (52) & $71 \cdot 3$ & $73 \cdot 5$ & II 71 & 59.4 & $54 \cdot 9$ \\
\hline \multicolumn{3}{|c|}{ Approx. SE of differences } & $2 \cdot 36$ & I·97 & III & $4 \cdot 31$ & $4 \cdot 06$ \\
\hline
\end{tabular}

* Values in parentheses are percentages of total dry-matter intake given intragastrically.

Table 2. Expt I. Mean values for the quantities of dry matter in the rumen of sheep and for rates of passage of stained particles and chromic oxide

\begin{tabular}{|c|c|c|c|c|c|c|}
\hline \multirow[b]{2}{*}{$\begin{array}{c}\text { Treatment } \\
\text { no. }\end{array}$} & \multicolumn{2}{|c|}{ Feed consumed } & \multicolumn{2}{|c|}{$\begin{array}{l}\text { Dry matter (g) in rumen (and } \\
\text { consumed in previous } 24 \mathrm{~h} \text { ) }\end{array}$} & \multicolumn{2}{|c|}{$\begin{array}{l}\text { Mean retention } \\
\text { time }(\mathrm{h}) \text { of }\end{array}$} \\
\hline & Orally & Intraruminally & $\begin{array}{l}\text { Before } \\
\text { feeding }\end{array}$ & $\begin{array}{c}\text { After } \\
\text { feeding }\end{array}$ & $\begin{array}{l}\text { Stained } \\
\text { particles }\end{array}$ & $\mathrm{Cr}_{2} \mathrm{O}_{3}$ \\
\hline $\mathbf{I}$ & Straw & Straw & $4 \times 5(197)$ & - & 86 & 85 \\
\hline 2 & Straw & Grass & $390(330)$ & $673(387)$ & 73 & 69 \\
\hline 3 & Grass & Straw & $818(929)$ & $1400(887)$ & 61 & 53 \\
\hline 4 & Grass & Grass & $596($ I I 58) & $1244(\operatorname{II} 16)$ & 59 & 47 \\
\hline \multicolumn{3}{|c|}{ Approx. SE of differences } & 100 & 105 & $9 \cdot 8$ & $8 \cdot I$ \\
\hline
\end{tabular}


experiment as a whole, fluctuations in the intake of individual sheep from day to day gave a coefficient of variation of $\mathrm{r} \cdot 8 \%$; the variation was slightly greater for treatments $I$ and 2 , in which straw was eaten (13.7\%) than for treatments 3 and $4(10.0 \%)$.

Digestibility and intake values for the four treatments are shown in Table I. The digestibility coefficients for the mixed diets (treatments 2 and 3 ) were quite close to one another and intermediate to those for treatments $I$ and 4 . Variability in intake was high, but the large differences between treatment means were significant (generally at the $\mathrm{r} \%$ level of probability). A large part of the difference in intake between

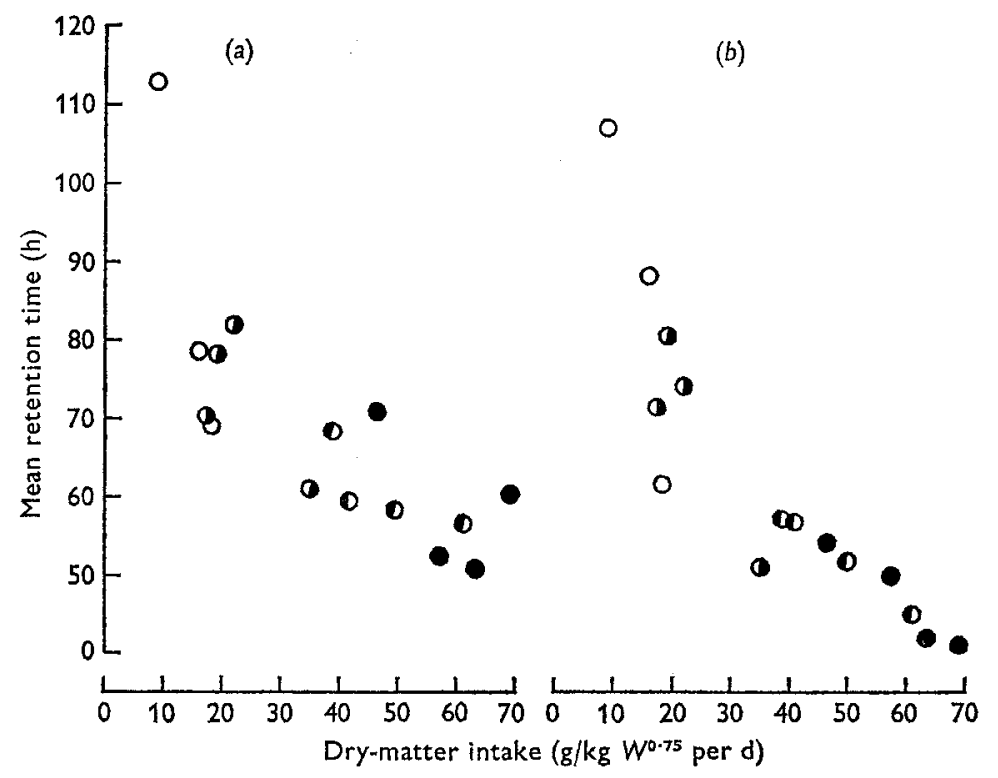

Fig. I. Mean retention time of (a) stained particles and (b) chromic oxide in sheep fed as follows: $O$, straw eaten, straw through fistula; $\bigcirc$, straw eaten, grass through fistula; $\bigcirc$, grass eaten, straw through fistula; 9 , grass eaten, grass through fistula.

treatments $I$ and 4 could be attributed to the effect of change in digestibility alone (cf. treatments $I$ and $2 ; 3$ and 4 ), but an equally large part was associated with changing the route of administration of the components (cf. treatments 2 and 3 ).

Estimates of the rate of passage of undigested residues, obtained from stained particle counts and from the chromic oxide content of faeces, are shown in Table 2 and are plotted against dry-matter intake in Fig. $x$.

The straw particles were always stained with brilliant green and the grass with basic fuchsin. In a later experiment (A. I. van Niekerk \& J. F. D. Greenhalgh, unpublished) it was found that if particles of the same chopped roughage were stained with these two dyes and given simultaneously to a sheep, the retention time for green particles was $8 \%$ lower, and that for red particles $8 \%$ higher, than the mean for the two colours. The explanation of this difference appeared to be that green particles tended to lose their colour while in transit through the sheep. In calculating the retention times, the observed times for green particles were therefore increased by $8 \%$ and those for red 
particles were reduced by the same proportion. The correlation coefficient for the times estimated with stained particles and those estimated with chromic oxide was 0.92; the two methods agreed when retention time was high (treatments $I$ and 2), but the chromic oxide was excreted faster than the stained particles when the retention time was_lower (treatments 3 and 4 ).

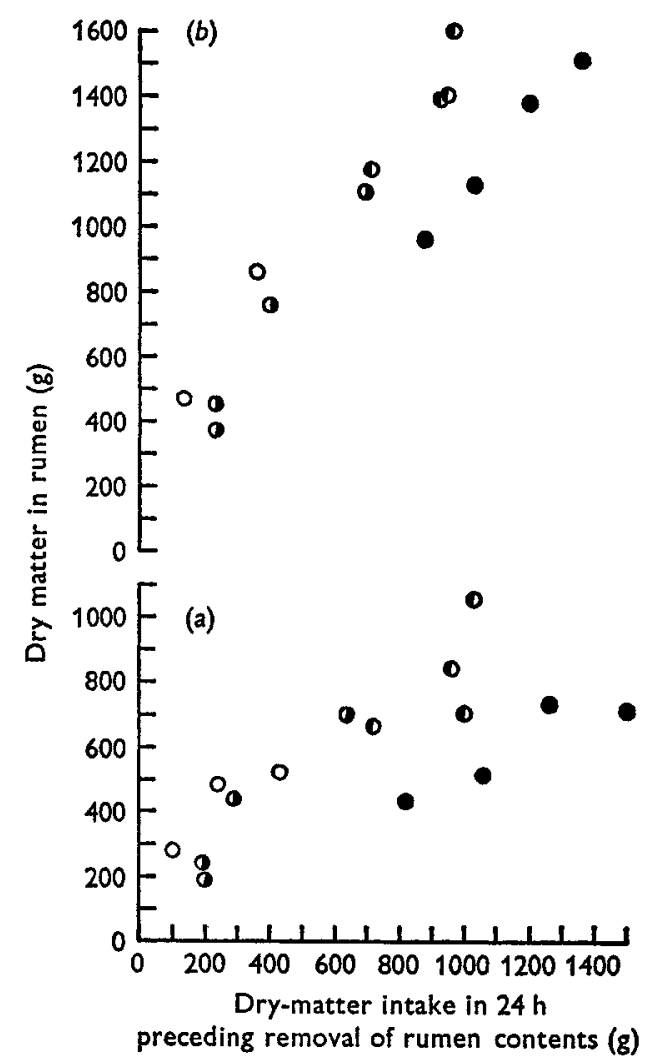

Fig. 2. Quantity of dry matter in the rumen, $(a)$ before and $(b)$ after feeding (each point represents one sheep): $O$, straw eaten, straw through fistula; $O$, straw eaten, grass through fistula; $\mathbf{D}$, grass eaten, straw through fistula; , grass eaten, grass through fistula.

Retention times were closely related to intake (Fig. I), and there was no evidence that these relationships differed between treatments. In other words, the effects of the treatments on retention time appeared to be due to their effects on intake.

The quantities of dry matter in the rumen before and after feeding are shown in Table 2 and Fig. 2. Most values are means for four sheep, each emptied on two occasions, but the results for treatments $\mathrm{I}$ and 2 are incomplete because the sheep went off feed. For treatment I, no reliable estimates were obtained for one sheep either before or after feeding, and for a second sheep after feeding, so no reliable mean value for rumen load after feeding could be calculated for this treatment. For treatment 2, the rumen of each sheep was emptied before and after feeding, but the rumens of two sheep were emptied only once at each time. 
The rumen load of a sheep is likely to be very much influenced by food consumed immediately beforehand. We have therefore included in Table 2 mean values for intake in the $24 \mathrm{~h}$ preceding the removal of rumen contents, which may be compared with values for intake measured over longer periods (Table $I$ ). The two sets of values differ appreciably only for treatment 2 when the rumen was emptied before feeding, and in this instance the value given in Table 2 is probably an underestimate of the rumen load generally associated with that treatment.

Rumen load differed markedly from one treatment to another, the greatest differences being between treatments $I$ and 2 on the one hand, and treatments 3 and 4 on the other. In Fig. 2 it appears that the relationships between rumen load and intake for treatment 4 differed from those for the other treatments. A graph prepared with values for total rumen contents (i.e dry matter plus water) showed a similar picture.

\section{Expt 2}

The digestibility coefficients for the grass (Table 3 ) were very close to those determined for the same feed in Expt I, but intake of dried grass was $12 \%$ higher in Expt 2 for no obvious reason. The digestibility coefficients for the mixed diets (treatments 2 and 3 ) were close to the mean of those for treatments $I$ and 4 . There was a large difference in intake between treatments $I$ and 4 ; a large proportion of this $(83 \%)$ could be attributed to differences between the feeds in digestibility and the rest to a difference in palatability $(17 \%)$. Day-to-day fluctuations in intake gave a coefficient of variation of $6.8 \%$.

Table 3. Expt 2. Digestibility and intake of diets based on hay and dried grass given alone or in combination to sheep

\begin{tabular}{|c|c|c|c|c|c|c|c|}
\hline \multirow{3}{*}{$\begin{array}{l}\text { Treat- } \\
\text { ment } \\
\text { no. }\end{array}$} & & & \multicolumn{2}{|c|}{ Digestibility of } & \multicolumn{3}{|c|}{ Daily intake of } \\
\hline & \multicolumn{2}{|c|}{ Feed consumed } & \multirow{2}{*}{$\begin{array}{c}\text { Dry } \\
\text { matter } \\
(\%)\end{array}$} & \multirow{2}{*}{$\begin{array}{c}\text { Organic } \\
\text { matter } \\
(\%)\end{array}$} & \multirow{2}{*}{$\begin{array}{l}\text { Dry } \\
\text { matter } \\
\text { (g) }\end{array}$} & \multirow{2}{*}{$\begin{array}{c}\text { Dry } \\
\text { matter } \\
\left(\mathrm{g} / \mathrm{kg} W^{0 \cdot 75}\right)\end{array}$} & \multirow{2}{*}{$\begin{array}{c}\text { Organic } \\
\text { matter } \\
\left(\mathrm{g} / \mathrm{kg} W^{0.75}\right)\end{array}$} \\
\hline & Orally & Intraruminally* & & & & & \\
\hline $\mathbf{I}$ & Hay & Hay (49) & $54 \cdot 0$ & $56 \cdot 3$ & 790 & $4 x \cdot 7$ & $39 \cdot 2$ \\
\hline 2 & Hay & Grass (5I) & $6 r \cdot 3$ & $62 \cdot 2$ & 1043 & $55^{\cdot} \mathrm{I}$ & $5 I \cdot I$ \\
\hline 3 & Grass & Hay (49) & $62 \cdot 3$ & $65 \cdot 3$ & I 176 & $59 \cdot 9$ & $55^{\circ} 5$ \\
\hline 4 & Grass & Grass (49) & $72 \cdot 0$ & $72 \cdot 5$ & I 33 I & $68 \cdot 7$ & $62 \cdot 7$ \\
\hline \multicolumn{2}{|c|}{ SE of differences } & & $I \cdot 13$ & $I \cdot 14$ & 74 & $2 \cdot 36$ & $2 \cdot 19$ \\
\hline 5 & Hay & - & $52 \cdot 9$ & $55^{\circ} \circ$ & 673 & $33 \cdot 8$ & $3 r \cdot 8$ \\
\hline 6 & Grass & - & $72 \cdot 2$ & $73 \cdot 6$ & 1216 & $60 \cdot 1$ & $56 \cdot 7$ \\
\hline \multicolumn{3}{|c|}{ SE of differences } & $\mathrm{x} \cdot 8$ & $2 \cdot I$ & 64 & $I \cdot 4$ & $I \cdot 3$ \\
\hline
\end{tabular}

* Values in parentheses are percentages of total dry-matter intake given intragastrically.

\section{Subsidiary trial}

In the subsidiary trial the differences in digestibility between hay and grass were very similar to those recorded in the main experiment, but the differences in intake between the feeds were relatively greater. Thus intake for treatment 5 (kg dry matter $/ \mathrm{kg} W^{0 \cdot 75}$ ) was $19 \%$ lower than that for treatment I in the main trial, but intake 
for treatment 6 was only $12 \%$ lower than that for treatment 4 . However, comparisons between the two parts of the experiment cannot be regarded as conclusive because of the possibility of time trends in intake.

\section{DISCUSSION}

Intake generally was lower in these experiments than in similar trials with sheep given various roughages (Blaxter et al. I961; Blaxter, Wainman \& Davidson, I966; Ulyatt, Blaxter \& McDonald, I967); the difference would in part be due to the fact that our sheep were offered food for only $7 \mathrm{~h}$ each day. In Fig. 3 we have compared the results of our experiments with those of three others in which one of the roughages

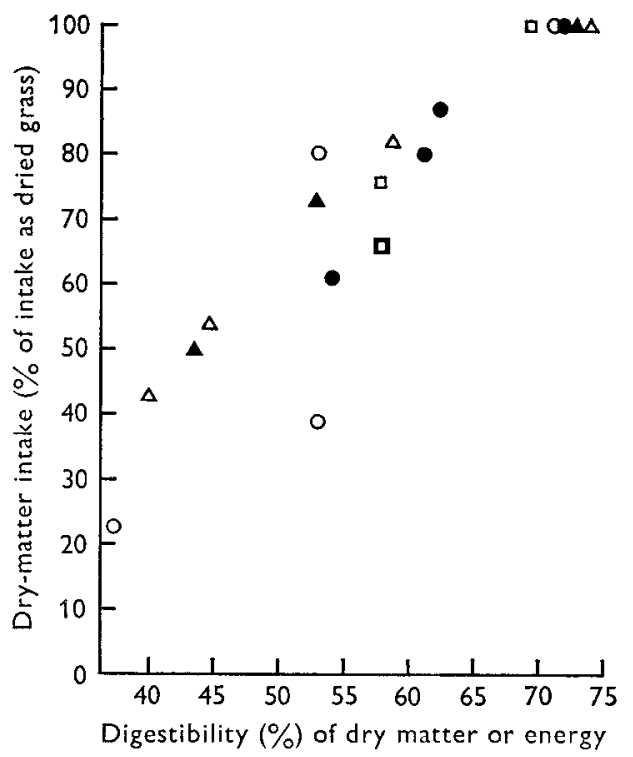

Fig. 3. Dry-matter intake in relation to diet digestibility for sheep fed on various roughages. Intake of dried grass, $69-74 \%$ digestible, is taken as 100 for each experiment. $O$, Expt I ; - Expt 2; $\triangle$, values of Blaxter et al. (I96I); $\Delta$, values of Blaxter et al. (1966); $\square$, values of Ulyatt et al. (1967).

was dried grass about $70 \%$ digestible. To bring the results to a common basis, the intake of the grass in each experiment has been given the value of 100 and intakes of the other roughages in that experiment have been calculated as percentages of driedgrass intake. When our sheep were given straw to eat (the two lowest intakes in Fig. 3), their intakes were unusually low, both in relation to intake of dried grass in the same experiment and to intake of other low-quality roughages in other experiments. Thus the sheep of Blaxter et al. (I966) ate $50 \%$ as much dry matter with oat straw as they did with dried grass, whereas in our experiment intake of straw alone was only $22 \%$ of that of grass alone. The question to be decided is whether our sheep ate straw in small quantities because it was unpalatable to them or because intake was restricted by other factors, particularly rate of digestion. Throughout the discussion it should be borne in mind that for half of Expt $\mathrm{I}$ the straw eaten contained $10 \%$ grass. 
We must first consider the validity of the technique used to measure palatability. Feeding through a fistula may retard digestion in the rumen, because it prevents mastication during eating and addition of saliva to the food. Bailey \& Balch (196I) gave cows the same ration of hay $(6.4 \mathrm{~kg} / \mathrm{d})$ either entirely by mouth or entirely by rumen fistula. They found that feeding by fistula had no effect on the digestibility of the hay, but it increased by $22 \%$ the quantity of dry matter in the rumen after feeding and increased by $42 \%$ the time spent by the animals in rumination.

Assessing the effect of feeding by fistula per se on intake is difficult if not impossible. At first sight it might seem that this effect could be measured by feeding animals to appetite with or without additions of the feed through the fistula. If total intake (oral plus intragastric) was the same with feeding by fistula as without, then the technique itself might be assumed not to affect intake. However, this is precisely the type of experiment made by Weston (1966) to measure the effect of palatability on intake. Weston concluded that since feed given intragastrically invoked a corresponding reduction in feed taken by mouth palatability was not determining intake, but it is possible that the reduction in oral intake took place because feeding by fistula retarded the rate of digestion in the rumen. Weston attempted to minimize any interference with the processes of digestion by coarsely milling the feed given by fistula (the sheep ate chopped feed), but he put dry feed into the rumen, which in our experience leads to an accumulation of digesta.

In our experiments, we attempted to avoid any effect of feeding by fistula per se by making it a constant feature of the treatments. Even so, it is possible that feeding by fistula may retard the digestion of some feeds and have little or no effect on the digestion of others. Thus it is possible that, in Expt I, chopped grass given by fistula was digested more slowly than coarsely milled straw, and that total intake was lower for treatment 2 (straw eaten and grass by fistula) than for treatment 3 (grass eaten and straw by fistula) because the grass caused digesta to accumulate in the rumen, rather than because the straw eaten was less palatable than the grass eaten. But the results for rumen load show no evidence of accumulation of dry matter with treatment 2 ; in fact, rumen load was generally twice as great for treatment 3 as for treatment 2 . In addition, the mean retention time of stained particles was, for both treatments, shorter for grass (treatment $2,70 \mathrm{~h}$; treatment $3,57 \mathrm{~h}$ ) than for straw (76 and $65 \mathrm{~h})$.

Treatments 2 and 3 provide the most interesting contrast of these experiments. As the two diets involved were almost identical in chemical composition and digestibility, and as there appeared to be no differences between them in rate of digestion other than those brought about by differences in intake, it seems difficult to explain the large difference between them in intake without involving the concept of palatability. There is a possibility, however, that chemostatic mechanisms played a part in controlling intake for treatments 2 and 3 . Additions to the rumen of grass (treatment 2) and straw (treatment 3 ) would be expected to differ in their effects on the concentrations of soluble nutrients in rumen liquor or on the rates of absorption of metabolites. But any differences of this kind would have been large for only a short time after the addition of feed to the rumen, because the effects of the feed given by 
fistula would soon have been counterbalanced by those of the contrasting feed eaten by mouth.

It is often suggested that ruminants fed on roughages so adjust their intake that rumen fill or load is kept constant. Ulyatt et al. ( 1967$)$ found that sheep with continuous access to one of two hays or to dried grass had an approximately constant volume of rumen fluid, as estimated by dilution of polyethylene glycol. Freer \& Campling (1963) observed that cattle given good-quality roughages for $4 \mathrm{~h} / \mathrm{d}$ had a constant rumen load at the end of this period. When straw and hay were compared, rumen load after feeding was lower for straw, but the two feeds promoted a constant load before feeding (Campling, Freer \& Balch, i96r).

In our Expt I, rumen load was not the same for all treatments, either before or after feeding; in fact, there appeared to be two sets of load levels, one for the treatments in which straw was eaten and the other for those in which grass was eaten. Thus, when straw was eaten, the animals stopped eating before the limits of their physical capacity were reached.

The conclusions drawn from these experiments are that palatability is probably not an important determinant of intake for better-quality roughages such as hay and dried grass, but that it may limit the intake of poor-quality roughages.

We thank Mr J. N. Aitken and Miss Helen Bean for counting the stained particles, Miss Shirley Gavin for the chemical analyses, Mr I. McDonald for the statistical analyses and the staff of the Duthie Experimental Stock Farm for the care of the sheep.

\section{REFERENCES}

Baile, C. A. \& Mayer, J. (r 967). Am. Y. Physiol. 213, 387.

Bailey, C. B. \& Balch, C. C. (196r). Br. F. Nutr. 15, I83.

Blaxter, K. L., Wainman, F. W. \& Davidson, J. L. (1966). Anim. Prod. 8, 75.

Blaxter, K. L., Wainman, F. W. \& Wilson, R. S. (196r). Anim. Prod. 3, 5 I.

Campling, R. C., Freer, M. \& Balch, C. C. (196I). Br. F. Nutr. 15, 531 .

Castle, E. J. (1956). Br. F. Nutr. Io, 15.

Corbett, J. L., Greenhalgh, J. F. D., McDonald, I. \& Florence, E. (I 960). Br. F. Nutr. x4, 289.

Freer, M. \& Campling, R. C. (1963). Br. Y. Nutr. 17, 79.

Greenhalgh, J. F. D. \& Reid, G. W. (r967). Nature, Lond. 214, 744.

Janowitz, H. D. \& Hollander, F. (1955). Ann. N.Y. Acad. Sci. 63, 56.

Marten, G. C. (1 969). Proc. natn. Conf. Forage Quality Evaluation, U.S.A. (Mimeo.)

Stevenson, A. E. \& de Langen, H. (1960). N. Z. Yl agric. Res. 3, 314.

Teitelbaum, P. \& Epstein, A. N. (1963). In Olfaction and Taste p. 347 (Y. Zotterman, editor]. Oxford: Pergamon Press.

Ulyatt, M. J., Blaxter, K. L. \& McDonald, I. (1967). Anim. Prod. 9, 463.

Weston, R. H. (1966). Aust. F. agric. Res. 17, 939. 